\title{
PROGRAM PEMBERDAYAAN SISWA TK DAN PAUD DI DESA DERMO MELALUI ALAT PERMAINAN EDUKATIF (APE) GUNA MENINGKATKAN DAYA KREATIVITAS SISWA
}

\author{
Dwi Rosita Dewi ${ }^{1}$, Khozainil Ulumiyah ${ }^{2}$, Siti Nur Khoiriyah ${ }^{3}$, \\ Shofiyatul Mashfah ${ }^{4}$, Lutfi Aprilliana ${ }^{5}$ \\ 1, 2, 3,4,5 Fakultas Keguruan dan Ilmu Pendidikan, Universitas PGRI Adi Buana Surabaya \\ email : dwirosita250395@gmail.com¹, khozainilulumiyah@gmail.com², sitinurkhoiriyah471@yahoo.com³, \\ shofiyatulmashfah@yahoo.co.id ${ }^{4}$, lutfiaprilliana13@gmail.com ${ }^{5}$
}

\begin{abstract}
This article is about how to make Games Education Tools (APE) whith shape playdough. Games Education Tools is an integral part in early childhood learning. Materials and tools used in the manufacture of playdough is flourm, salt, water, food coloring, and oil. The goal of this activity is a kindergarten and PAUD in Dermo village. In this activity, the kindergarten and PAUD in the village Dermo very are enthusiastic in making and creation of playdough. This activity uses the method description. The purpose of Games Education Tools is to develop fine motor skills and vision, develop socio-emotional abilities, and develop cognitive abilities (intelligence). the Games Educational Tool has advantage for childrens that can learn and play safely. It does not only children can understand the colors and learn the creativity by using playdough as a game.
\end{abstract}

Keywords: Games Educational Tool, (APE), and playdough

\begin{abstract}
Abstrak
Artikel ini tentang pembuatan alat permainan edukatif berbentuk playdough. Alat permainan edukatif merupakan bagian yang tidak terpisahkan dalam pembelajaran anak usia dini. Bahan dan alat yang digunakan dalam pembuatan playdough adalah Tepung terigu, garam, air, pewarna makanan, dan minyak. Sasaran dari kegiatan ini adalah anak TK dan PAUD di desa Dermo. Dalam kegiatan ini, anak-anak TK dan PAUD di desa Dermo sangat antusias dalam membuat dan mengkreasikan playdough. Kegiatan ini menggunakan metode deskripsi. Dalam kegiatan ini, anak-anak TK dan PAUD di desa Dermo sangat antusias dalam membuat dan mengkreasikan playdough. Tujuan permainan edukatif adalah untuk mengembangkan keterampilan motorik halus dan wawasan berpikir, mengembangkan kemampuan sosial-emosional, dan mengembangkan kemampuan kognisi (kecerdasan). Dengan memanfaatkan Alat Permainan Edukatif (APE) anak dapat belajar dan bermain dengan aman. Tidak hanya itu anak juga bisa mengenali warna dan belajar berkreasi dengan menggunakan permainan playdough.
\end{abstract}

Kata Kunci : Alat Permainan Edukatif, (APE), dan playdough

\section{PENDAHULUAN}

Alat permainan edukatif merupakan bagian yang tidak terpisahkan dalam pembelajaran anak usia dini (TK KB TPA SPS). Ketersediaan alat permainan tersebut sangat menunjang terselenggaranya pembelajaran anak secara efektif dan menyenangkan sehingga anak-anak dapat mengembangkan berbagai potensi yang dimilikinya secara optimal.

Dunia pendidikan tingkat kanak-kanak adalah sebuah dunia yang tidak terlepas dari bermain dan juga berbagai alat permainan anakanak. Salah satu lembaga pendidikan yang berperan penting dalam proses pembelajaran dan peningkatan mutu dunia pendidikan kanak-kanak adalah Taman Kanak-Kanak yang disingkat menjadi TK dan Kelompok Bermain yang disingkat menjadi $\mathrm{KB}$ maupun disebut PAUD. Sebagai sebuah taman pendidikan tertentu TK dan PAUD merupakan sebuah tempat belajar dan juga bermain kanak-kanak yang memiliki berbagai sarana dan pra sarana untuk mendukung terlaksanannya proses pembelajaran dengan baik dan berkualitas.

Salah satu sarana yang juga menjadi sumber belajar bagi anak di TK dan PAUD adalah alat pendidikan edukatif yang lebih dikenal dengan APE. Menurut Mayke Sugianto T. dalam Badru Zaman, dkk (2007:63) alat permainan edukatif adalah permainan yang sengaja dirancang secara khusus untuk kepentingan pendidikan. Sementara Badru Zaman (2007:63) alat permainan edukatif 
adalah alat permainan yang dirancang untuk tujuan meningkatkan aspek-aspek perkembangan anak TK. Alat ini bisa didapatkan dengan cara membelinya dari produsen alat-alat permainan anak atau juga bisa dengan membuatnya sendiri. Pada umumnya para penyelenggara pendidikan TK, PAUD dan juga para guru masih banyak yang membeli alat-alat permainan untuk sumber belajar anak. Hal ini tentu saja akan menumbuhkan budaya konsumtif dan akan melemahkan daya kreativitas dan inovasi para guru dalam menyelenggarakan proses belajar yang berkualitas bagi anak.

Secara umum banyak para penyelenggara pendidikan TK, PAUD dan guru yang berpendapat bahwa memperoleh Alat Pendidikan Edukatif dengan cara membeli adalah lebih mudah dan ekonomis. Namun jika para guru mau berkreasi dan berinovasi untuk menciptakan Alat Pendidikan Edukatif dari barang-barang yang mudah diperoleh maka tentu saja akan lebih ekonomis lagi.

Banyak mainan sekarang ini yang semakin kreatif, mahal dan beraneka macam. Tentunya hal ini akan banyak membuat orang tua bingung. Banyak mainan yang dibuat oleh pabrik yang sebetulnya kurang bermanfaat bagi anak-anak karena sebenarnya alat bermain hanyalah alat bantu saja bagi seorang anak dan bukan merupakan indikator mutlak untuk anak berkembang lebih baik. Jadi mahal dan murahnya alat mainan bukanlah merupakan indikator. Anak akan dapat bermain dengan manfaat yang besar apabila orang tua dapat mengetahui sisi kegunaan mainan tersebut.

Berdasarkan kerangka pemikiran yang ada bahwa Alat Pendidikan Edukatif tidak mesti alat permainan yang mahal maka penulis berupaya mencoba mengembangkan dan membuat sebuah APE. Sebelum membuatnya tentu saja penulis harus mengetahui tentang pengertian, fungsi dan prosedur pembuatan APE untuk menjadi salah satu sumber belajar di TK dan PAUD. Penulis akan coba mengembangkan permainan Playdough yang aman dimainkan oleh anak-anak. Permainan ini diberi nama Playdough dan yang akan dibahas dalam tulisan ini secara khusus dirancang untuk memberikan pengalaman belajar kognitif dan afektif kepada para pemainnya sehingga dapat dikategorikan sebagai permainan edukatif.

Berdasarkan latar belakang tersebut, peneliti merumuskan masalah sebagai landasan terfokus untuk mengetahui tentang pembuatan dan pengembangan Alat Pendidikan Edukatif di TK dan PAUD Desa Dermo. Adapun rumusan masalahnya sebagai berikut : (1) Bagaimana pengertian Alat Permainan Edukatif di TK dan PAUD Desa Dermo? (2) Bagaimana pentingnya penggunaan Alat Pendidikan Edukatif di TK dan PAUD Desa Dermo? (3) Bagaimana cara Pengembangan Alat Pendidikan Edukatif di TK dan PAUD Desa Dermo? dan (4) Bagaimana cara Pembuatan Alat Pendidikan Edukatif di TK dan PAUD Desa Dermo?.

Berdasarkan permasalahan yang telah dipaparkan sebelumnya maka tujuan dari penulisan makalah ini adalah: (1) Untuk mengetahui pengertian Alat Pendidikan Edukatif di TK dan PAUD Desa Dermo. (2) Untuk mengetahui pentingnya penggunaan Alat Pendidikan Edukatif di TK dan PAUD Desa Dermo. (3) Untuk mengetahui bagaimana cara pembuatan dan pengembangan alat pendidikan edukatif di TK dan PAUD Desa Dermo. (4) Untuk menjadi mendorong guru untuk lebih inovatif dan kreatif dalam membuat dan mengembangkan alat pendidikan edukatif di TK dan PAUD Desa Dermo.

\section{METODE}

\section{A. Sasaran Kegiatan}

Target dari kegiatan ini adalah TK dan PAUD desa Dermo. Dalam proses belajar, anak-anak tidak terlepas dari bermain dan juga berbagai alat permainan anak-anak. Oleh sebab itu APE sangat cocok untuk diaplikasikan kepada anak TK dan PAUD .

B. Metode Kegiatan

Kegiatan ini menggunakan metodi deskripsi:
1) Mendeskripsikan langkah-langkah pembuatan playdough.
2) Mengaplikasikan langkah-langkah pembuatan playdough.
3) Mengkreasikan playdough menjadi beberapa bentuk hewan.

C. Langkah-langkah kegiatan
1) Menyiapkan bahan.
2) Menyiapkan alat.
3) Melaksanakan pembuatan.

D. Faktor Pendukung dan Penghambat

1) Faktor Pendukung

a) Bahan mudah di dapat.

b) Bahan murah dan aman. 
c) Antusias anak-anak TK dan PAUD sangat tinggi.

2) Faktor penghambat

a) tidak ada

E. Alat dan Bahan Kegiatan

1) Alat

Baskom dan sendok.

2) Bahan

Tepung terigu, garam, air, pewarna makanan, dan minyak.

\section{HASIL DAN PEMBAHASAN}

Permainan edukatif merupakan suatu kegiatan yang sangat menyenangkan. Permainan edukatif merupakan cara atau alat pendidikan yang bersifat mendidik dan bermanfaat untuk meningkatkan kemampuan berbahasa, berpikir serta bergaul dengan lingkungan atau untuk menguatkan dan menterampilkan anggota badan si anak, mengembangkan kepribadian, mendekatkan hubungan antara pendidik dengan peserta didik, kemudian menyalurkan kegiatan anak didik dan sebagainya.

Dunia anak adalah dunia bermain, melalui bermain anak memperoleh pelajaran yang mengandung aspek perkembangan kognitif, sosial, emosi dan perkembangan fisik. Melalui kegiatan bermain dengan berbagai permainan anak dirangsang untuk berkembang secara umum baik perkembangan berpiikir, emosi maupun sosial.

TK dan PAUD merupakan tempat belajar sekaligus bermain bagi anak-anak. Anak-anak diajarkan mengenal aturan, disiplin, tanggung jawab dan kemandirian dengan cara bermain. Anak juga diajarkan bagaimana mereka harus menyesuaikan diri dengan lingkungannya, berempati dengan temannya, tentunya juga berlatih bekerja sama dengan anak yang lain.

Melalui kegiatan bermain yang mengandung edukasi, daya pikir anak terangsang untuk merangsang perkembangan emosi, perkembangan sosial dan perkembangan fisik. Setiap anak memiliki kemampuan dan ketertarikan bermain yang berbeda tergantung dari perkembangan anak. Dari permainan juga biasanya akan menimbulkan fantasi-fantasi besar oleh anak, dan tentu akan semakin menambah rasa ketertarikan anak pada mainan tersebut.

Tujuan permainan edukatif bagi anak usia dini adalah untuk mengembangkan keterampilan motorik halus dan wawasan berpikir anak, mengembangkan Kemampuan Sosial-Emosional, dan mengembangkan Kemampuan Kognisi (Kecerdasan).

Pada artikel ini akan dipaparkan penerapan Alat Permainan Edukatif (APE) yaitu pembuatan playdough untuk anak TK dan PAUD di desa Dermo. Dalam kegiatan ini, anak-anak TK dan PAUD di desa Dermo sangat antusias dalam membuat dan mengkreasikan playdough. Anakanak diajarkan bagaimana cara membuat playdough atau yang biasanya disebut dengan malam. Anak-anak dengan semangat mengikuti langkah demi langkah agar menghasilkan malam dengan bahan yang alami dan sudah tidak asing lagi di mata mereka, karena memang bahanbahan yang digunakan untuk membuat playdough adalah bahan-bahan yang mudah didapat, antara lain, tepung terigu, pewarna makanan, dan minyak goreng.

Terdapat beberapa langkah yang harus dilakukan dalam pembuatan playdough agar menghasilkan hasil yang sesuai. Langkah pertama yang harus dilakukan adalah mempersiapkan bahan dan alat yang diperlukan untuk pembuatan playdough. Langkah selanjutnya adalah mencampurkan semua bahan menjadi satu dalam satu wadah. Kemudian mengaduk adonan hingga kalis. Langkah selanjutnya yaitu memberikan warna pada adonan sesuai selera anak-anak. Setelah adonan selesai dibuat, anak-anak mulai berkreasi sesuai dengan imajinasi mereka. Hasil yang mereka buat antara lain yakni binatang, tumbuhan, dan juga huruf-huruf dari nama mereka.
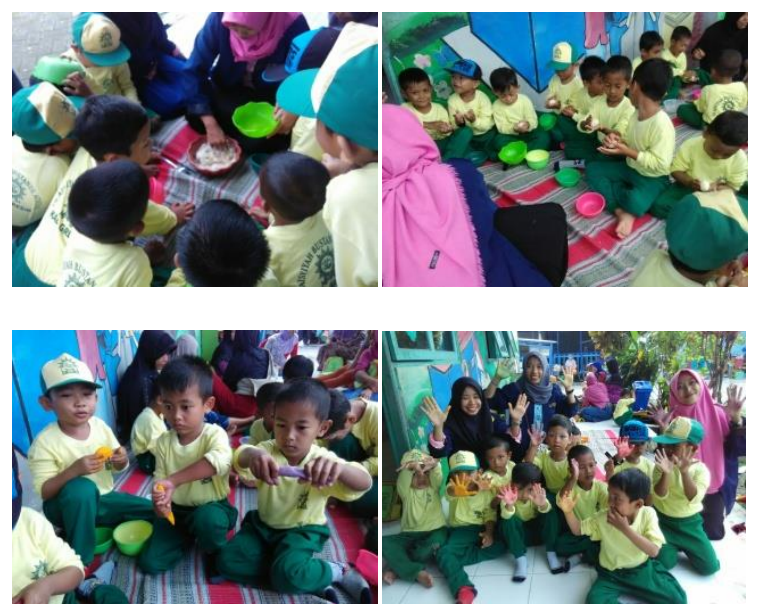


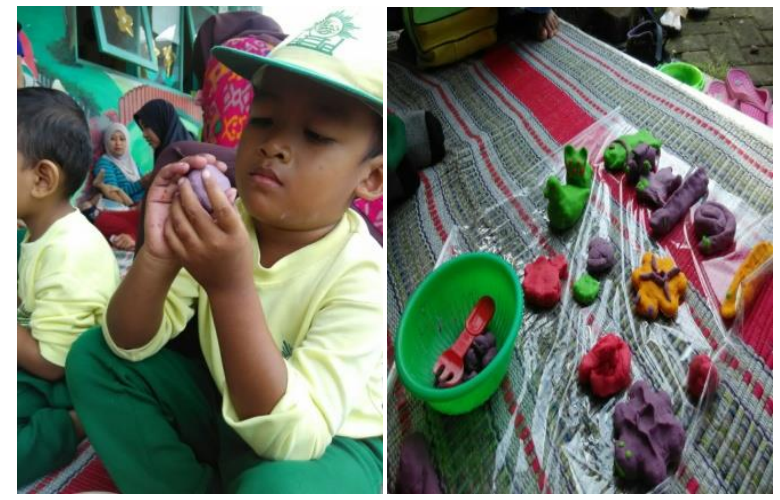

Gambar 1. Alat Permainan Edukatif (APE) di TK Aisyiyah Bustanul Athfal 37 Desa Dermo Kecamatan Benjeng Kabupaten Gresik
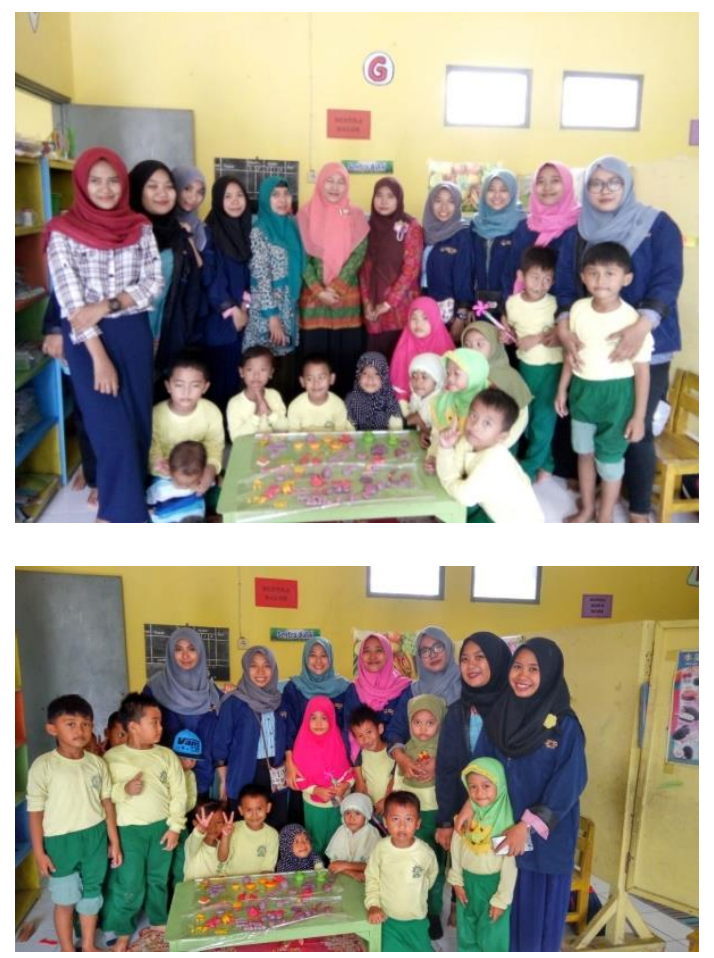

Gambar 2. Alat Permainan Edukatif (APE) di PAUD Aisyiyah Bustanul Athfal 37 Desa Dermo Kecamatan Benjeng Kabupaten Gresik

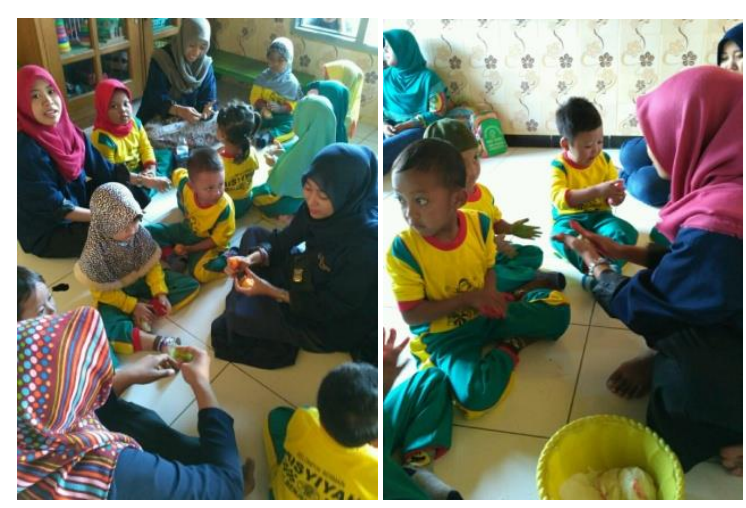

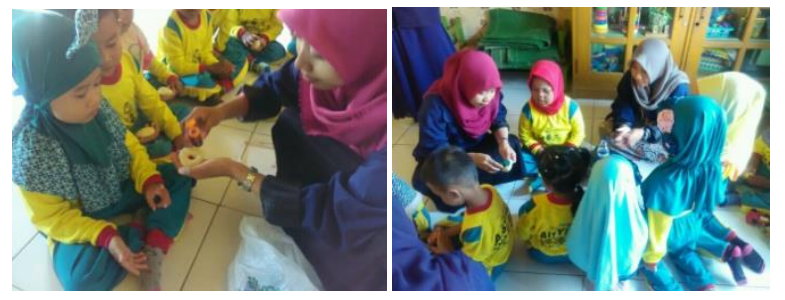
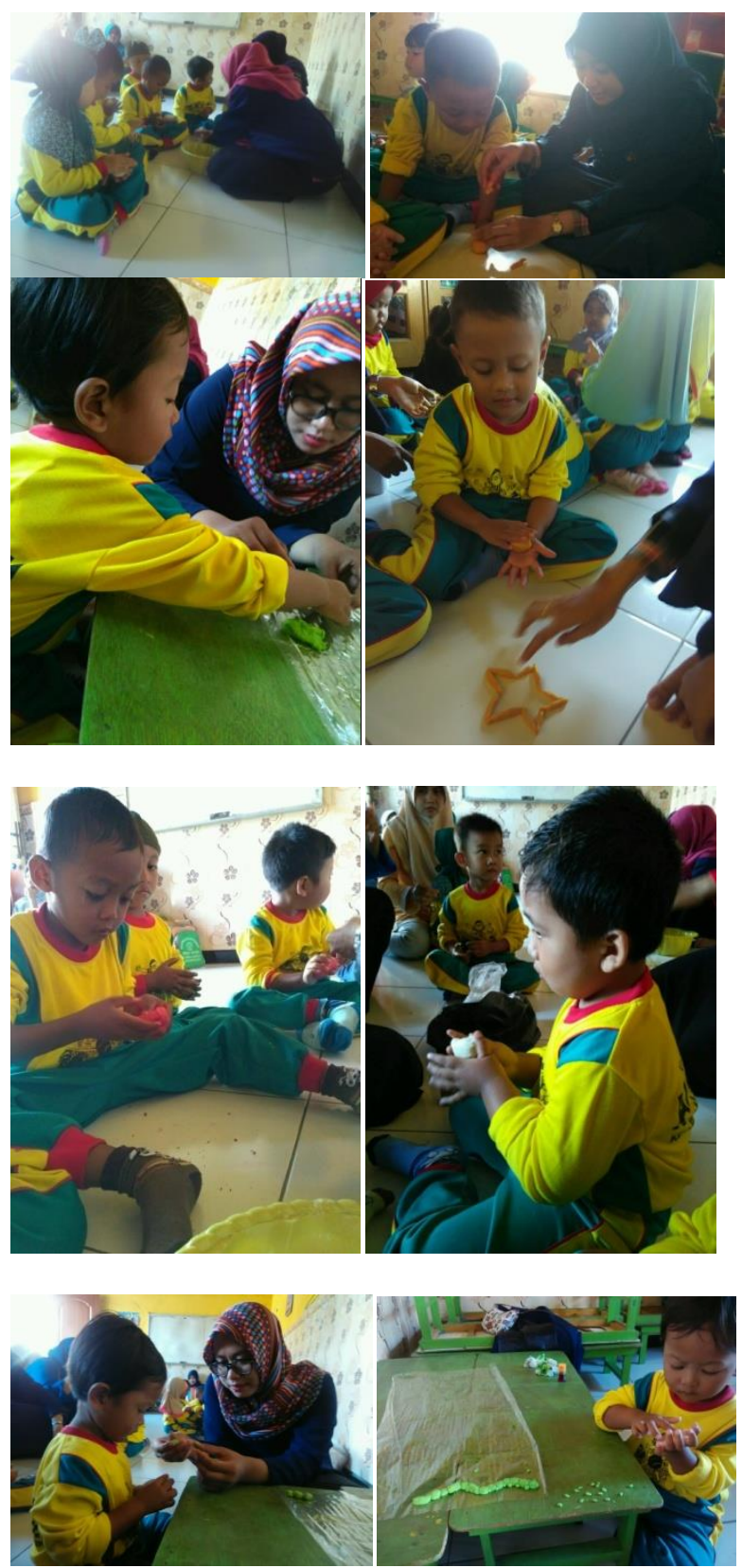

Gambar 3. Aktivitas Siswa PAUD di PAUD Aisyiyah Bustanul Athfal 37 Desa Dermo Kecamatan Benjeng Kabupaten Gresik 

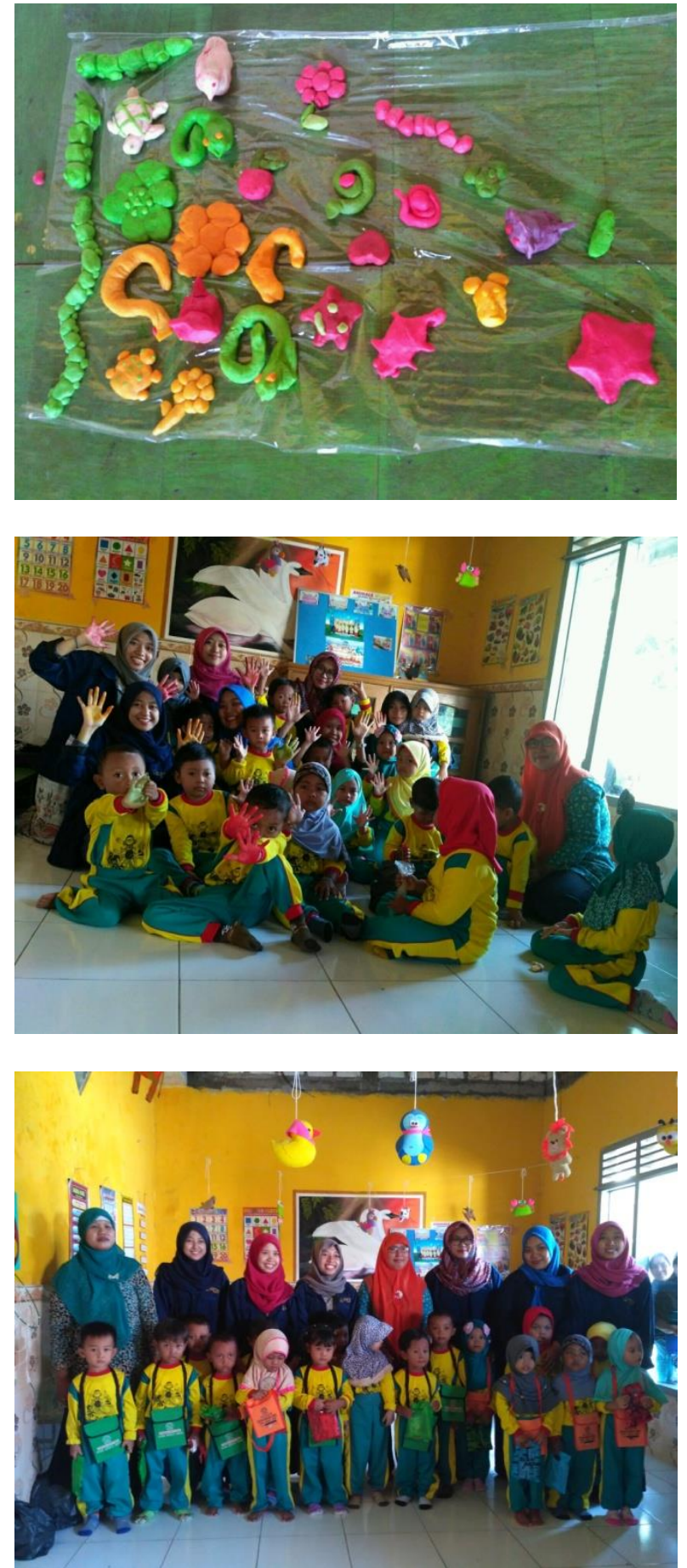

Gambar 4. Hasil Karya APE siswa PAUD Aisyiyah Bustanul Athfal 37 Desa Dermo Kecamatan Benjeng Kabupaten Gresik

\section{KESIMPULAN}

Permainan edukatif merupakan sebuah bentuk kegiatan mendidik yang dilakukan dengan menggunakan cara atau media permainan yang bersifat mendidik. Tujuan permainan edukatif adalah untuk mengembangkan keterampilan motorik halus dan wawasan berpikir, mengembangkan kemampuan sosial-emosional, dan mengembangkan kemampuan kognisi (kecerdasan). Dengan memanfaatkan Alat Permainan Edukatif (APE) anak dapat belajar dan bermain dengan aman. Tidak hanya itu anak juga bisa menganali warna dan belajar berkreasi dengan menggunakan permainan playdough.

\section{REFERENSI}

Riastypurwandari.blogspot.com/2014/05/permain an-edikatif-sebagai-media.html=1

Lailakhoiris.wordpress.com/makalah-ape/

Saramoe-

printstation.blogspot.com/2013/01/makalahalat-permainan-educatif-ape.html $? \mathrm{~m}=1$

Paudjateng.xahzgs.com/2015/08/pengertian-apepaud-alat-permainan-edukatif.html? $\mathrm{m}=1$ 
ABADIMAS ADI BUANA Volume 02, Nomer 2, 01 Oktober 2017 